\section{Kulturfolger Ragweed}

\section{Ragweedpollen gehören zu den weltweit wichtigsten Allergenen, etwa 10\% der US-Bevölkerung sind gegen die Pollen verschiedener Ambrosia-Spezies sensibilisiert. Das Unkraut gedeiht offenbar vorzüglich unter den klimatischen Gegebenheiten von größeren Städten.}

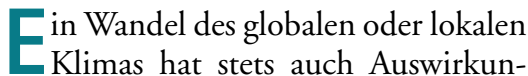
gen auf die Flora. Eine Studie untersuchte den Einfluss klimatischer Veränderungen in der Umgebung von Städten auf das Wachstum sowie die Pollenproduktion von Ambrosia artemisiifolia und Ambrosia trifida, den beiden häufigsten Ragweedarten in den USA. Dazu wurden in den Jahren 2000 und 2001 die durchschnittlichen Tageswerte der $\mathrm{CO}_{2}$-Konzentration und der Temperatur in verschiedenen Gegenden des US-Bundesstaates Maryland gemessen.

In urbanen Siedlungsbereichen lagen die $\mathrm{CO}_{2}$-Konzentrationen um $30-31 \%$ und die Temperaturen um $1,8-2,0^{\circ} \mathrm{C}$ höher als in ländlichen $\mathrm{Ge}$ bieten - Unterschiede, wie sie in dieser Größenordnung bereits auf der ganzen Welt dokumentiert wurden. In den urbanen Gegenden wuchs Ragweed schneller, blühte früher und produzierte signifikant mehr Pollen als seine Artgenossen auf dem Lande. Außerdem enthielt der ,städtische“ Pollen mehr Allergene.

Während der Grund für den letzten Punkt noch unklar ist, dürfte die Ursache für die erhöhte Biomasseproduktion in der $\mathrm{C}_{3}$-Typ-Photosynthese von Ragweed liegen: Bei einer solchen Photosynthese ist das Pflanzenwachstum durch Kohlenstoff limitiert, ein erhöhtes Angebot von $\mathrm{CO}_{2}$ in der Luft wirkt daher bei solchen Pflanzen wie ein Dünger. Zusätzlich beschleunigt sich die Stoffwechselrate durch die erhöhten Temperaturen.

Fazit: Das Kleinklima urbaner Siedlungsräume mit seinen höheren Temperaturen und $\mathrm{CO}_{2}$-Konzentrationen führt zu einer Veränderung der Vegetation mit einer möglicherweise erhöhten Produktion von Allergenen. In den USA ist die Produktion von Ragweed-

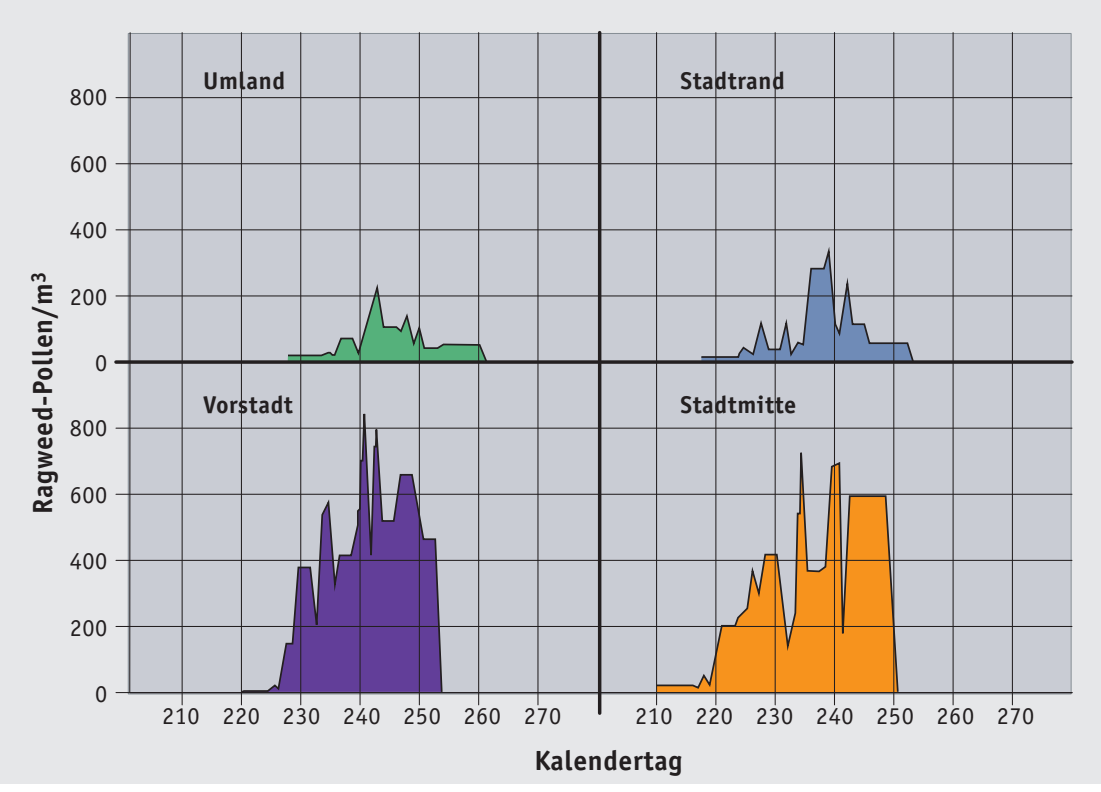

Durchschnittlicher Tagesausstoß von Ragweedpollen während der Blütezeit im Jahr 2001 im Vergleich verschiedener Gegenden im US-Bundesstaat Maryland

\section{Ragweed auf dem Vormarsch}

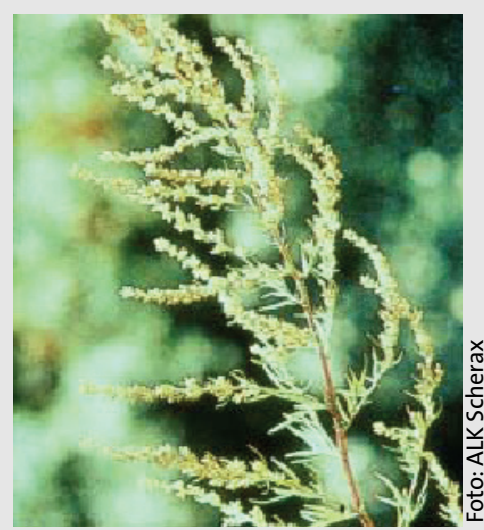

Das Traubenkraut - üblicher ist auch in Deutschland die englische Bezeichnung Ragweed - ist den USA der häufigste Allergieauslöser. Seit dem Zweiten Weltkrieg breitet sich die unscheinbare Pflanze aus der Familie der Korbblütler ausgehend vom französischen Rhonetal und der ungarischen Tiefebene - auch in Europa aus. Große Populationen existieren in Südfrankreich, Ungarn, Österreich, der Slowakei, Tschechien und Polen. Das Kraut wurde aber auch schon in Südschweden und Norditalien nachgewiesen. In Deutschland vermehrt sich Ragweed recht erfolgreich im Frankfurter Raum.

Es gibt in Italien und den USA radikale Bekämpfungsprogramme, die die Ausbreitung der Pflanze verhindern sollen. So gibt es in manchen Staaten der USA sogar Strafen für Gartenbesitzer, auf deren Grünflächen Ragweed gefunden wird. Der Siegeszug des Unkrauts konnte dadurch aber bisher kaum gebremst werden.

Prof. Dr. Karl-Christian Bergmann befürchtet: „Wahrscheinlich wird sich Ragweed europaweit ausbreiten." In seiner Klinik in Bad Lippspringe wurde schon bei mehreren Patienten eine Sensibilisierung gegen Ragweed festgestellt. „Noch ist unklar, wie viele tatsächlich unter Symptomen leiden. Wir müssen diese Pflanze aber zunehmend bei der Allergiediagnostik berücksichtigen."

pollen um die Städte herum deutlich höher als in ländlichen Gebieten. $\quad b k$

Ziska LH et al. Cities as harbingers of climate change: common ragweed, urbanization, and public health. J Allergy Clin Immunol 2003; 111: 290-5 